\title{
Identificação de áreas de recarga de aquíferos e suas interfaces com áreas propícias à urbanização
}

\author{
SERAPHIM, Ana Paula Albuquerque Campos Costalonga ${ }^{1}$ \\ BEZERRA, Maria do Carmo de Lima ${ }^{2}$ \\ ${ }^{1}$ Grupo de Pesquisa de Gestão Ambiental Urbana da Universidade de Brasília, Brasília, Brasil. anapaula313@gmail.com \\ 2Grupo de Pesquisa de Gestão Ambiental Urbana da Universidade de Brasília, Brasília, Brasil.mdclbezerra@gmail.com
}

\section{Resumo}

O artigo visa contribuir para a discussão sobre as alterações do regime hidrológico decorrentes da urbanização, especialmente no que tange a recarga dos aquíferos. O foco de análise é a identificação dos fatores do meio físico intervenientes na recarga de aquíferos e na escolha de áreas para urbanização, dados necessários para espacialização dessas áreas e para subsidiar tomadas de decisão à uma urbanização mais sensível a água. Como método se utilizou ferramentas do planejamento ecológico para expressar por meio de mapas as áreas a serem preservadas e/ou ocupadas com padrões urbanos que mitiguem a perda dos serviços ecossistêmicos derivados da recarga de aquíferos. O caso estudado é o Distrito Federal onde se demonstra que mais de $80 \%$ da área urbana consolidada está sob áreas de recarga, exigindo uma revisão das tipologias de ocupação.

Palavras-Chave:Áreas de recarga de aquíferos; Áreas propícias à Urbanização;Urbanismo Sensível a Água; Planejamento urbano ecológico;

\begin{abstract}
The article aims to add to the discussion about the changes in the hydrological regime due to urbanization, especially concerning the aquifers recharge. The analysis focus is the identification of the physical environmental factors intervener in aquifer recharge and in the choice of areas for urbanization, data needed to spatialize these areas and subsidize decision making for water-sensitive urbanization. As a method, ecological planning tools were used to express through maps the areas to be preserved and/or occupied with urban typologies that mitigate the loss of ecosystem services derived from the recharge of aquifers. The case studied is the Federal District where it is demonstrated that more than $80 \%$ of the consolidated urban area is under recharge areas, requiring a revision of the typologies of urban occupation.
\end{abstract}

Key-Words: Aquifer recharge areas; Areas Suitable for Urbanization, Water Sensitive Urban Design; Urban Ecology; 


\section{Introdução}

Está consagrado no conhecimento científico e, até, no senso comum que a urbanização altera significativamente o regime hidrológico, levando a consequências que causam alteração ou perda de importantes serviços ecossistêmicos como: de substrato à vida; de fornecimento de insumo ao sistema produtivo; de assimilação de resíduos gerados por atividades antrópicas; de utilidades estéticas e de lazer; e de base para a regulação climática do planeta. Nesse contexto, a preservação dos recursos hídricos é imperativa.

Entretanto, ainda persiste defasagem de instrumentos e práticas do planejamento urbano para lidar com o tema.As consequências negativas da urbanização convencional, no que tange o ciclo hidrológico, estão relacionadas desde a escolha das áreas a serem ocupadas até o padrão de cobertura do solo adotado. Neste tipo de urbanização, desvinculado da base ecológica do território,corpos d'água são canalizados, efluentes sem tratamento lançados ao ambiente, áreas de mananciais desmatadas e áreas de especial interesse para a recarga de aquíferos impermeabilizadas.

Entre esses, a observância da alteração do processo de recarga nas cidades se impõe pela notada sobreposição das áreas de recarga e de áreas urbanizadas e o papel estratégico dos aquíferos nos cenários de escassez hídrica. Sendo que, os impactos negativos da urbanização na recarga dos aquíferos são de dois tipos: (i) na quantidade, devido às alterações nas taxas de infiltração; e (ii) na qualidade, devido a intrusão de contaminantes de forma indireta ou direta (FOSTER, STEPHEN; LAWRENCE; MORRIS, 1998).

No que se refere à quantidade de água infiltrada se destacam o aumento da impermeabilização do solo e redução de cobertura vegetal (MARSALEK et al., 2013). A proporção de água que infiltra no solo após a precipitação pode variar de 50\%, em ambientes naturais, para 30 a $15 \%$ dependendo do tipo de ocupação do solo urbano (MOTA, 1981; HOUGH, 1985). Essa condição associada a retirada de água dos aquíferos para abastecimento podem levar diminuição significativa do volume de água disponível, podendo causar rebaixamento do lençol freático, diminuição da vazão de descarga de água nos corpos hídricos superficiais e subsidência do solo. Entretanto, também existem nas cidades diversas fontes de recarga artificial não intencional. Foster, Morris e Lawrence (1994) estimaram, em casos extremos, que vazamentos não intencionais do sistema de esgotamento e abastecimento de água podem ser equivalentes a $500 \mathrm{~mm}$ de chuva ao ano em áreas altamente povoadas.

O problema desse aumento da recarga por meio de processos não intencionais é que, na maioria dos casos, suas fontes acabam por introduzir contaminantes na água do subsolo. Um elevado número de atividades humanas urbanas podem poluir os aquíferos através de recargas não intencionais, sendo as principais fontes contaminadoras: os (1) aterros controlados ou não controlados; (2) tanques e as lagoas usados para tratar, evaporar ou armazenar resíduos líquidos de drenagem, industriais ou minerais, que costumam desenvolver vazamentos; (3) tanques subterrâneos usados para armazenar líquidos como gasolina, que geralmente desenvolvem vazamento devido a corrosão e conexões ruins; (4) águas residuais, que podem escorrer de fossas sépticas, latrinas, encanamento de esgoto ou serem diretamente descarregadas no solos; (5) transporte de água contaminada em canais abertos e rios que recarregam aquíferos; (6) indústrias, principalmente as que lidam com resíduos tóxicos, como hidrocarbonetos, solventes sintéticos, metais pesados, etc.; e (7) locais de enterro de humanos e animais, quando os caixões usados não são estanques (MARSALEK et al., 2013) .

Ainda, há casos nas cidades de recarga artificial intencional a partir de técnicas de drenagem sustentável, que visam o aumento das oportunidades para retenção e infiltração da água da chuva. As principais técnicas de drenagem sustentável, que auxiliam na infiltração da água, são (HINMAN, 2012): (1) sistemas de infiltração, como células, trincheiras e cobertores de infiltração; (2) bacias de bioretenção ou jardins de chuva, que são pequenas depressões projetadas com um mix de solo e 
plantas, que utilizam as propriedades químicas, biológicas e físicas destes para reter, infiltrar e remover poluentes da água; e (3) compostagem dos solos, uma vez que a matéria orgânica é capaz de fisicamente e quimicamente melhor a estrutura e porosidade do solo.

Dentro desta problemática, de redução e poluição dos aquíferos a partir da urbanização convencional de suas áreas de recarga, o estudo visa contribuir para o ajuste das bases técnicas do planejamento urbano propiciando uma ferramenta espacial de identificação das áreas de interseção entre áreas de recarga e áreas propícias à urbanização, onde é importante a adoção de padrões de urbanização que permitam maior infiltração natural da água da chuva. Novas medidas de urbanização que geram um menor impacto ao ciclo hidrológico vem sendo propostas desde 1970, como a Low Impact Development (LID), Water Sustainable Urban Design (WSUD) e Sustainable Drainage Systems (SuDS). Entretanto, sua adoção, quando existente, ainda comparece de forma muito pontual e nem sempre são priorizadas as áreas de recarga (SOUZA; CRUZ; TUCCI, 2012).

Existe uma quantidade significativa de estudos, principalmente, na área de hidrogeologia que procuram entender o processo de recarga dos aquíferos e identificar suas áreas de ocorrência, a exemplo de: Simmers (1987), Lousada e Campos (2005), Bear (2007), e Santos e Koide (2016). Também, existem estudos, principalmente, na área da ecologia urbana, que procuram verificar características do meio físico que condicionam a urbanização, como: McHarg (1969), Mota (1981), e Hough (1984). Entretanto, ainda são reduzidos estudos que relacionam as condicionantes da recarga dos aquíferos e do processo de urbanização.

Assim, a partir de uma revisão bibliográfica desses temas, a pesquisa constrói um arcabouço teórico e metodológico capaz de auxiliar na identificação de áreas propícias à recarga dos aquíferos e áreas propícias à urbanização. E num segundo momento se aplica a metodologia na análise do estudo de caso, o território do Distrito Federal-DF escolhido devido: (i) à problemática recente que tem vivido em relação à escassez de água; (ii) alto grau de urbanização, que coloca a relação forma urbana -impacto na recarga em evidência; e (iii) substancial base de informações sobre a dinâmica socioambiental do território que remonta aos estudos para implantação da capital quando foi elaborado o Relatório Cruls, até o recente estudo do zoneamento ecológico econômico - ZEE/DF, de onde foram obtidos a maioria dos dados do meio físico do DF.

\section{Matérias e Método}

Como método para identificação das áreas propícias à recarga de aquíferos e à urbanização foram utilizadas técnicas de planejamento ecológico de sobreposição de informações cartográficas, que permitem visualizar a distribuição espacial de processos naturais e antrópicos e suas relações.Essa metodologia permite a tomada de decisão sobre alternativas de ocupação que medeiem ações humanas e processos naturais, sendo que a dimensão espacial dada aos processo ecológicos oferece uma linguagem comum para interação entre planejamento urbano e ecologia (LETÃO; AHERN, 2002).

De acordo com Ndubisi (2002), as principais abordagens de planejamento ecológico foram desenvolvidas na década de 1960 por Hills em 1961, Lewis em 1963 e McHarg em 1969. Essas abordagens envolvem: (1) o levantamento de características do meio físico que influenciam o fenômeno estudado; (2) a organização dessas características em padrões espaciais; (3) a valoração desses padrões de acordo com seu desempenho em relação ao fenômeno estudado; e (4) o relacionamento desses valores com usos antrópicos.

A partir de 1980, os avanços no sensoriamento remoto e o desenvolvimento da tecnologia de Sistemas de Informação Geográfica (GIS) permitiram a ampliação dessas metodologias. Nessa linha se destaca a abordagem desenvolvida por Crepani et al. (2001) para elaboração de cartas de vulnerabilidade/potencialidade de ocorrência de processos ecossistêmicos para orientar atividades de intervenção antrópica. A técnica classifica o grau de potencialidade por meio da atribuição de valores 
às características do meio físico de temas individuais. Esses valores recebem posteriormente um valor final, resultante de média aritmética dos valores individuais, onde, para cada tema, podem ser atribuídos pesos iguais ou diferentes a depender de sua importância para o tema.

Essa técnica foi adaptada ao estudo, com os dados analisados no programa ArcGis, para resultar em mapas de sobreposição de padrões espaciais com características do meio físico semelhantes e com pesos atribuídos de acordo com sua aptidão para a recarga dos aquífero e urbanização. As características do meio físico consideradas para construção dos mapas foram selecionadas de acordo com sua influência no processo de recarga e de urbanização.

\subsection{Identificação das Condicionantes físicas do Processo de Recarga de Aquíferos}

A separação dos recursos hídricos em águas superficiais e subterrâneas é artificial, já que na verdade elas fazem parte de um sistema conectado, o ciclo hidrológico, e qualquer mudança em um desses componentes afeta eventualmente o outro. Entretanto essa separação é importante para o estudo e gestão do comportamento da água. As formações subterrâneas podem ser divididas verticalmente em zonas de acordo com a proporção de água nos poros do solo. Essencialmente, temos uma zona de saturação onde os poros estão preenchidos principalmente com água e uma zona de aeração onde os poros estão preenchidos principalmente com gases. A zona saturada é normalmente delimitada por uma superfície imaginária denominada lençol freáticao, abaixo da qual se encontram os aquíferos.

A parte mais superficial da zona de aeração é responsável por manter a água da qual depende a vegetação, sendo que a umidade dessa zona durante a precipitação influencia a quantidade de água que se move para as camadas inferiores. Esse fenômeno está relacionado com a capacidade de campo, que corresponde ao volume de água adsorvido que fica parado por forças capilares, sofrendo movimento apenas para cima por evaporação ou transpiração vegetativa (TEIXEIRA et al., 2000; BEAR, 2007). Após essa camada superficial a água se move para baixo por gravidade em direção aos aquíferos. Acima do lençol freático, ocorre a subzona capilar, considerada praticamente saturada e com espessuras que variam até $1 \mathrm{~m}$, onde existe também um fluxo horizontal, configurando o escoamento subsuperficial que pode alimentar rios ou nascentes (BEAR, 2007).

Os aquíferos se dividem em confinados e não confinados, livres ou freáticos. A recarga dos aquíferos freáticos dá-se de forma direta pelas camadas superiores do solo principalmente por meio da precipitação ${ }^{1}$. Enquanto a recarga dos aquíferos confinadas se dá principalmente a partir de aquíferos freáticos adjacentes, por meio de camada semipermeável ou permeável, ou por áreas específicas na superfície onde a camada confinante termina. Em condições naturais, o total da água precipitada que infiltra no solo em direção aos aquíferos, livres ou confinados, depende principalmente dos seguintes fatores: topografia; altura, intensidade e duração da chuva; capacidade de campo, umidade antecedente e propriedades hidráulicas do solo (BEAR, 2007; MOTA, 1981; SIMMERS, 1987). Esses fatores supracitados podem agrupados em características relacionadas com: (i) o clima; (ii) a geomorfologia; e (iii) a pedologia.

Do clima importa principalmente as características da precipitação de altura, intensidade e duração. A altura é importante já que para a água chegar a infiltrar seu volume precisa ser maior do que as perdas que ocorrem por interceptações, evapotranspiração, retenção em depressões e infiltração até a saturação da camada superficial do solo. Ainda, chuvas menos intensas, regularmente distribuídas ao longo do tempo, promovem uma infiltração maior, pois a velocidade de infiltração pode acompanhar a altura de precipitação gerada, enquanto chuvas torrenciais favorecem o escoamento superficial direto. A duração das chuvas também é relevante, já que a taxa de infiltração da água no solo decresce quando o solo se encontra saturado.

\footnotetext{
${ }^{1} \mathrm{Em}$ alguns casos a água da recarga natural também pode ser proveniente de corpos hídricos superficiais e quantidades muito pequenas podem ser de origem magmática.
} 
A geomorfologia influência a recarga por meio da: (1) altitude relativa e (2) declividade. O padrão do fluxo de movimento da água entre as áreas de recarga e descarga ocorre a partir da força da gravidade e pressão, normalmente de áreas mais elevadas para áreas menos elevadas, formando bacias hidrográficas subterrâneas, que acompanham o relevo do terreno (SIMMERS, 1987). Assim, os altos regionais são responsáveis por recargas dos aquíferos mais profundos, enquanto áreas baixos regionais, por recargas locais, que são logo descarregadas nos corpos hídricos superficiais (SILVEIRA; USUNOFF, 2009). Somado a isso, os declives acentuados, acima de $20 \%$, favorecem o escoamento superficial direto, diminuindo a infiltração (KALIRAJ; CHANDRASEKAR; MAGESH, 2014).

Das características do solo são importantes principalmente: capacidade de campo; umidade antecedente; profundidade e condutividade hidráulica. A umidade do solo anterior à precipitação influencia a infiltração da água que chega aos aquíferos devido à capacidade de campo do solo, sendo que a primeira camada de água adsorvida quando o solo está pouco úmido contribui apenas para completar essa capacidade, não sofrendo movimentos para níveis inferiores (BEAR, 2007). A condutividade hidráulica do solo é o fator mais decisivo em relação às taxas de infiltração (SANTOS; KOIDE, 2016; LOUSADA \& CAMPOS, 2005). Os solos mais porosos e permeáveis, em geral com maior teor de areia, possuem altas taxas de infiltração. Enquanto solos mais finos e de menor porosidade, em geral com maior teor de argila, possuem menores taxas de infiltração. Além disso, a espessura do solo também importa, uma vez que tem a capacidade de reter temporariamente uma maior quantidade de água precipitada que posteriormente é liberada para o aquífero subjacente.

\subsection{Identificação das Condicionantes do Processo de urbanização}

A escolha das áreas onde ocorre o processo de urbanização envolve uma multiplicidade de fatores socioeconômicos, culturais e políticos, de proteção e ambientais, que se sobrepõe e variam no tempo e espaço (CARTER, 1977). Em relação às condicionantes ambientais da urbanização, autores da área da ecologia urbana apontam que os principais fatores do meio físico a serem contemplados para a escolha de áreas a serem urbanizadas são: (1) o clima; (2) a geomorfologia; e (3) os solos (HOUGH, 1984; MCHARG, 1969; MOTA, 1981).

Os fatores climáticos que estão mais relacionadas ao conforto térmico e, consequentemente, a escolha de locais a serem urbanizados devem considerar: (1) a radiação solar; (2) a temperatura; (3) a velocidade e direção dos ventos; (4) a precipitação; (5) a umidade; e (6) as camadas atmosféricas (BARBIRATO; TORRES; SOUZA, 2011). Esses fatores dependem principalmente, da altitude, longitude e continentalidade dos locais (MOTA, 1981). Ainda no clima, a presença de chuvas é um fator importante para a escolha dos locais a serem urbanizados, uma vez que está relacionado à disponibilidade hídrica local, recurso indispensável à vida e ao desenvolvimento.

Da geomorfologia, a declividade é o fator que mais influencia a urbanização (MOTA, 1981). Terrenos com grandes declividades podem ser inapropriados à ocupação devido a problemas de instabilidade e dificuldade de mecanização. De forma a precaver situações de risco e impactos dessa natureza o artigo $3^{\circ}$ da Lei Federal 6.766/79 estabelece um limite de declividade de 30\% $\left(15^{\circ}\right)$ para o loteamento do solo urbano. Mas mesmo para declividades entre 20 a $30 \%$ já se recomenda o uso de técnicas adequadas à conservação dos solos. Em adição, os baixos regionais geralmente estão associados a alta densidade de drenagens naturais e estão mais sujeitas a inundações e inversões de temperatura das camadas atmosféricas, que podem contribuir para o agravamento da poluição do ar.

Os solos, também influenciam na escolha da área e no tipo de ocupação. Por exemplo, a instabilidade de ocupação de encostas depende da coesão do solo, sendo que, quanto mais coeso o solo menos propício à deslizamentos. Também, as propriedades do solo são fundamentais para determinar condições para a sustentação de obras civis, sendo importante: a permeabilidade, a profundidade, a resistência ao cisalhamento e resistência à carga. A resistência a cargas é determinada principalmente 
pelas características de coesão e compacidade do solo. Em linhas gerais, areias compactas e argilas rijas, duras e profundas, representam solos melhores para fundações, com maior capacidade de suporte de carga e menos susceptíveis a deformações (ALMEIDA, 2004). Entretanto, solos considerados com boas características para fundações, devido principalmente a sua compacidade, acarretam em limitações ao desenvolvimento da arborização urbana, infiltração da água e capacidade de receber efluentes líquidos domésticos. Em adição, solos encharcados de regiões pantanosas ou próximas a drenagens naturais, com lençóis freáticos muito altos, também são inadequados devido susceptibilidade à deformação, risco de inundações, contaminação e dificuldade de receber efluentes domésticos.

\subsection{Similaridade entre áreas propícias à recarga e à urbanização}

A comparação dos fatores do meio físico relevantes ao processo de urbanização e ao processo de recarga dos aquíferos permite inferir o grau de similaridade de aptidão dessas áreas. Em relação ao clima, para uma maior recarga dos aquíferos, é necessário que haja grande altura de precipitações constantes, pouco intensas e de curta duração. Enquanto, para urbanização é necessário que haja disponibilidade hídrica, relacionada com a grande altura de precipitações e com padrões geomorfológicos que permitam a armazenagem desse recurso. Em relação a geomorfologia, é importante menor declividade e maior altura regional nos dois casos, sendo que a menor declividade se destaca em relação a altura regional para a urbanização. Quanto aos solos, importa para a recarga a permeabilidade e profundidade, enquanto para a urbanização importa tanto a performance para infiltração, quanto maior resistência a cargas. Somado a isso, a maior ocorrência dos solos com melhores características para a recarga e para a urbanização costumam acontecer justamente em áreas de planaltos, que por serem altos regionais também são mais propícias a recarga regional e urbanização, o que demonstra por fim a grande semelhança entre as condicionantes do meio físico desses dois processos.

Tabela 1: Relação entre os fatores do meio físico propícios à recarga de aquíferos e propícios à urbanização.

\begin{tabular}{|c|c|c|c|}
\hline $\begin{array}{c}\text { Caracterização } \\
\text { necessária }\end{array}$ & Fatores relacionados à recarga & $\begin{array}{c}\text { Fatores relacionados à } \\
\text { urbanização }\end{array}$ & Relação \\
\hline Geomorfologia & $\begin{array}{l}\text { Regiões topográficas de maior } \\
\text { altitude e menor declividade }(<20 \%)\end{array}$ & $\begin{array}{l}\text { Regiões topográficas de maior } \\
\text { altitude e menor declividade }(<30 \%)\end{array}$ & $\begin{array}{l}\text { Muito } \\
\text { alta }\end{array}$ \\
\hline Solos & $\begin{array}{l}\text { Solos permeáveis e espessos, com } \\
\text { umidade antecedente à chuva } \\
\text { próxima a capacidade de campo }\end{array}$ & $\begin{array}{l}\text { Solos mais compactos e espessos, } \\
\text { que possuem ao mesmo tempo } \\
\text { resistência a cargas e capacidade de } \\
\text { absorção }\end{array}$ & Alta \\
\hline Clima & $\begin{array}{l}\text { Grande quantidade de chuvas, } \\
\text { pouco intensas e de curta duração }\end{array}$ & $\begin{array}{l}\text { Temperaturas e umidades amenas, } \\
\text { disponibilidade hídrica }\end{array}$ & Alta \\
\hline
\end{tabular}

\section{Estudo: Áreas Propícias à Recarga e à Urbanização no DF}

A área de estudo se caracteriza por conformações naturais que não levam a retenção de águas superficiais e por clima composto de um período chuvoso e um período seco fazendo com que os aquíferos tenham função estratégica para: (i) manutenção das vazões superficiais na época de seca; (ii) reservatório natural de estocagem estratégica de água; e (iii) abastecimento de núcleos rurais e urbanos.

Algumas cidades do Distrito Federal como São Sebastião, Jardim Botânico, Incra-8, Sobradinho, Arapoanga, Itapoã, Papuda, Água Quente e 47 comunidades rurais são abastecidas com poços tubulares profundos, que representam cerca $6 \%$ do total de água distribuída pela CAESB - Companhia de Saneamento Ambiental do Distrito Federal. Além da água advinda da rede de abastecimento, áreas residências em Sobradinho, Planaltina, São Sebastião e Jardim Botânico e parte dos bairros do Lago Sul, Lago Norte e Park Way, também exploram água de aquíferos rasos para abastecimento doméstico urbano. Já no setor industrial e no comércio e serviços o uso de água subterrâneas é comum em casos 
onde não se exige água tratada. Os setores que se destacam nesses uso são os postos de gasolina, lava-jatos, empresas de transporte, clubes, ramos industriais de bebidas, alimentos e cimento. Também na agropecuária, o cultivo de hortifrúti, criação de animais e abatedouros costuma utilizar água subterrânea para irrigação por meio de poços pouco profundos.

Segundo Campos (2004), em áreas residências informais da região de Sobradinho já se observa a redução da quantidade de água subterrânea desde os anos 2000, onde um poço com vazão de 10.000 $\mathrm{l} / \mathrm{h}$ em 1992 passou a uma vazão de cerca de $3.500 \mathrm{l} / \mathrm{h}$, na área denominada Alto Bela Vista. A crise hídrica pela qual o DF passou entre o final de 2016 e meio de 2018, também acometeu os reservatórios de água subterrânea, de modo que, devido diminuição de vazão e falhas na captação, a CAESB teve que fazer redução de pressão e rodízio de abastecimento também em Brazlândia, Sobradinho I e II, Planaltina, Fercal e São Sebastião ${ }^{2}$, áreas abastecidas por água subterrânea.

A redução da quantidade de água nos aquíferos não pode ter sido causada por mudanças recentes no regime de chuvas, uma vez que o tempo de deslocamento da água nos reservatórios subterrâneos é bastante lento. Pesquisa de Lousada e Campos (2006) mostra que mesmo as águas mais rasas dos aquíferos freáticos apresentam idades, em média, mais velhas que 5 anos, enquanto as águas mais profundas apresentam idades mais antigas que 30 anos. Ou seja, os impactos percebidos, principalmente nos poços profundos operados pela CAESB, demonstram que há outros fatores envolvidos na situação de escassez hídrica no DF, que não apenas as mudanças climáticas.

Esse contexto,mostra que a redução de vazão dos aquíferos no DF está relacionada também com mudanças no padrão de ocupação do solo, demonstrando a importância da gestão do ciclo da água, em especial a função de recarga dos aquíferos, integrada a política de planejamento territorial na região. Entretanto, segundo Oliveira et al. (2015) e Santos \& Koide (2016) ainda é pequena a atenção dada à estudos desenvolvidos para a região para a quantificação de taxas de recarga e caracterização espacial do processo, sendo que ainda não existem valores precisos de taxas de recarga associadas aos diferentes tipos de solo e cobertura. Entretanto, alguns estudos que procuraram estimar taxas de infiltração em áreas de cerrado stricto sensu, relatam taxas que variam entre $20 \%$ a $60 \%$ da altura precipitada a depender do tipo de solo (SANTOS; KOIDE, 2016; OLIVEIRA et. al, 2015), demonstrando a importância da vegetação desse bioma para a infiltração. Também sabe-se que a condutividade hidráulica do solo é o fator mais importante na regulação da recarga em áreas de cerrado (SANTOS; KOIDE, 2016) e que a recarga dos aquíferos rasos se dá principalmente por meio da precipitação (CAMPOS, 2004) e dos aquíferos profundos principalmente a partir dos aquíferos rasos (LOUSADA \& CAMPOS, 2005).

Existem atualmente dois mapas que procuram estimar a distribuição espacial da recarga dos aquíferos no DF desenvolvidos no âmbito do governo local. Um deles foi desenvolvido por Gonçalvez (2007) e é utilizado pela agência reguladora de águas do Distrito Federal - ADASA. Esse mapa cruzou dados de: (1) tipos de cobertura do solo; (2) propriedades hidrológicas dos solos; (3) pluviometria média; (4) e declividade. Os parâmetros do mapa foram agregados e o resultado desse cruzamento foi traduzido numa porcentagem potencial de infiltração da água da chuva (ver figura 1). No entanto, de acordo com Mello e Castro (2011), os valores de taxa de infiltração do referido mapa são ainda apenas uma aproximação sujeita a muita incerteza.

O outro mapa de recarga foi desenvolvido no âmbito do ZEE/DF para compor um de seus quatro mapas de riscos ecológicos. Esse mapa mensura o nível do risco de redução da recarga e produção hídrica dos aquíferos a partir do cruzamento de: (1) condutividades hidráulicas do domínio dos aquíferos porosos; (2) compartimentações geomorfológicas; e (3) níveis de vazão dos domínio dos

\footnotetext{
${ }^{2}$ Resolução n 21 da Agência Reguladora de águas, energia e saneamento básico do Distrito Federal - ADASA, de 08 de setembro de 2018
} 
aquíferos profundos fraturados e físsuro-cársticos, geralmente utilizados para o abastecimento (GDF, 2017). Para o cruzamento desses fatores foram atribuídos valores para cada uma das variáveis que representam de forma crescente o risco de redução da recarga e produção hídrica. Esses valores foram agregados, utilizando média ponderada, onde, devido a importância da condutividade hidráulica para o fenômeno medido, está teve peso duplo (ver figura 2).

Figura 1: Mapa do potencial de recarga dos aquíferos do DF. Fonte: Gonçalvez, 2007.

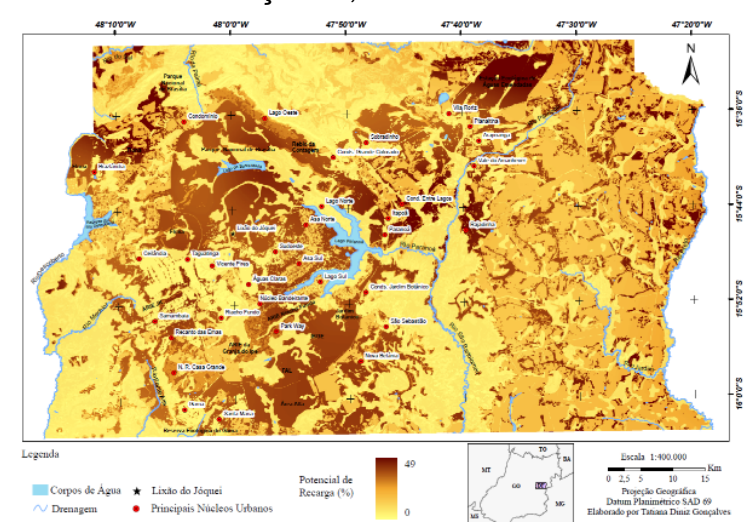

Figura 2: Mapa de risco ecológico de perda de recarga de aquífero - ZEE/DF. Fonte: GDF, 2017.

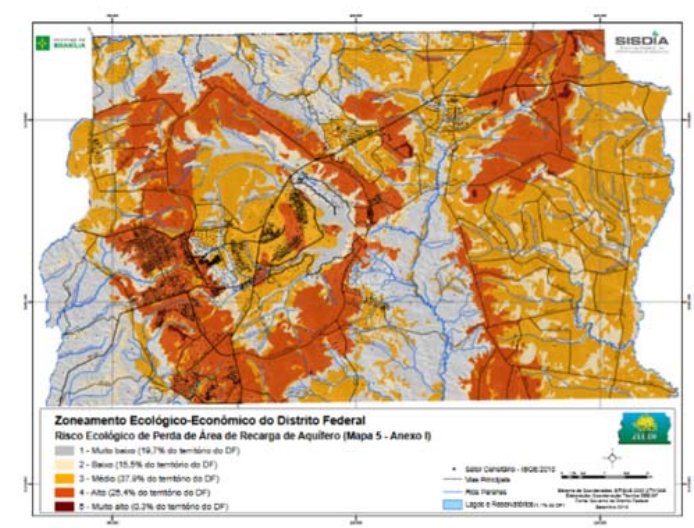

Esses mapas possuem relevância na caracterização da recarga no DF, entretanto não se adequam diretamente a análise da presente pesquisa, dado que o objetivo da mesma é verificar as zonas de maior potencial à recarga natural dos aquíferos, com base nas características do meio físico revisadas conforme metodologia apresentada na seção anterior. O objetivo é identificar como a base natural do território favorece ou dificulta esse processo, sem atribuir valores fixos ao potencial de recarga de diferentes coberturas do solo, como no mapa da ADASA ou levar em consideração também a questão da produção hídrica, como no mapa do ZEE/DF.

\subsection{Características do meio físico do Distrito Federal}

À vista dessas questões, para identificação das áreas propícias à recarga e à urbanização, foi feita revisão das características do meio físico que condicionam o processo de recarga e de urbanização e que podem ser analisadas principalmente por meio do estudo de dados da geomorfologia, pedologia e clima, como revisado na seção anterior.

Em relação a geomorfologia, em 2011, o relatório do meio físico e biótico elaborado pelo ZEE/DF (GDF; GREENTEC, 2011), integrou e adaptou abordagens de Novaes Pinto (1994) e Martins \& Baptista (1998) definindo cinco compartimentos para o DF, a saber: Planos Elevados, Planos Intermediários, Vales Dissecados, Rebordos e Rampas Íngremes. Essa proposta considera o padrão de relevo, a declividade, o grau de dissecação e a densidade de drenagem. Os planos elevados e intermediários representam os melhores sítios para recarga dos aquíferos e ocupação urbana, uma vez que esses são os altos regionais, com altitudes superiores a 1100 metros e entre 950 e 1050 metros respectivamente, possuem as menores declividades, inferiores a $12 \%$, e solos mais profundos, permeáveis e bem estruturados. As áreas de rebordo possuem declividade que varia entre 10 e $20 \%$ e presença de solos de média permeabilidade que são menos adequados para recarga e para ocupação urbana, devendo essa se preocupar com a implantação de infraestrutura adequada para conservação dos solos nessas áreas. Os vales dissecados são menos efetivos em termos da contribuição para a recarga, pelas altas declividades superiores a $20 \%$ e por serem o baixo regional, com altas densidades de drenagem, o que também limita a ocupação urbana. Já, as rampas íngremes possuem declividades acentuadas, acima de $25 \%$, e presença de solos rasos e pouco permeáveis, contribuindo pouco ou nada para a recarga e possuindo sérias restrições à ocupação urbana devido à alta suscetibilidade a ruptura e erosão. 
Quanto à pedologia, no DF são três as classes de solos mais representativas em termos de distribuição espacial: latossolos vermelhos e vermelho-amarelos ( $54 \%$ da área do Distrito Federal) e Cambissolos Háplicos (31\%). Há ainda outras classes de ocorrência mais restrita, porém, de importância significativa, que merecem destaque: Gleissolos, Nitossolos, Plintossolos, Neossolos Quartzarênicos, Neossolos Flúvicos e Chernossolos (GDF; GREENTEC, 2011; LOUSADA; CAMPOS, 2005; SOUZA, 2013). Os Latossolos Vermelho e Vermelho-amarelo permitem qualquer tipo de uso urbano, com edificações de diferentes portes, subsolo, instalação de sistemas de saneamento in situ e possuem, de forma geral, os maiores valores de condutividade hidráulica vertical, apresentando as melhores condições para recarga natural e artificial, sendo muito importantes para a produção hídrica na região e para ocupação urbana. Enquanto, as áreas que são recobertas por Cambissolos Háplicos, de modo geral, possuem as piores condições para recarga, mas podem ser ocupadas nas áreas de menor declividade. Nesse caso, se deve ter atenção a preservação do solo devido sua suscetibilidade à erosão e evitando a instalação de sistemas de saneamento in situ e subsolos. Nos outros $15 \%$ do território, os Neossolos Quartzarênicos, Nitossolos e Argissolos, apresentam algumas limitações à ocupação urbana, sendo que o Neossolos Quartzarênico, diferente dos demais, possui alta condutividade hidráulica, contribuindo para recarga. Já os Neossolos Flúvicos e Gleissolos Háplicos devem ser vinculados exclusivamente a preservação ambiental, devido sua sensibilidade a inundações, presença de matéria orgânica e alta plasticidade. Os Plintossolos não contribuírem para recarga e são adequados para ocupação urbana, devido sua alta resistência e estabilidade.

Figura 3: Compartimentação geomorfológica do Distrito Federal. Fonte: GDF \& Greentec, 2011

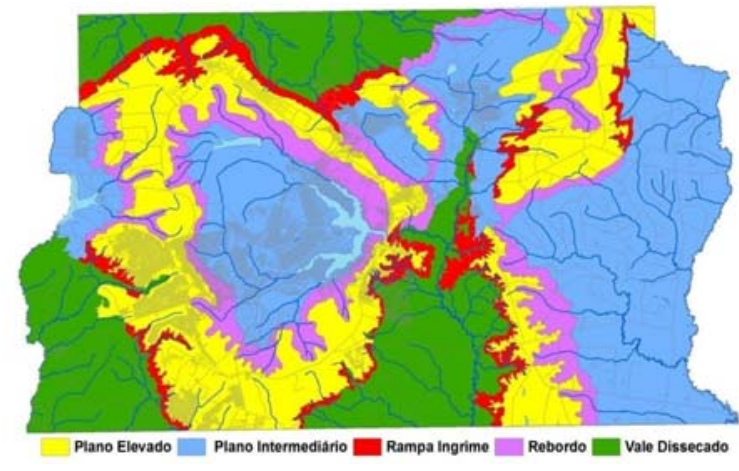

Figura 4: Mapa de solos do Distrito Federal. Fonte: GONÇALVEZ 2007, modificado de EMBRAPA, 1978.

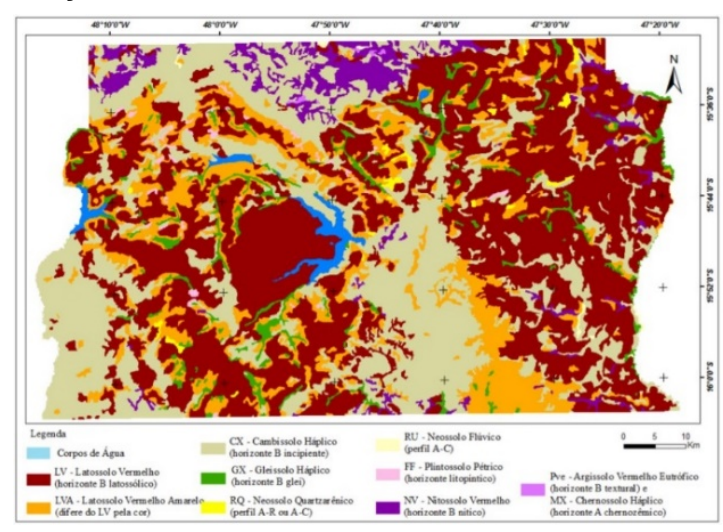

Quanto ao clima, de acordo com a classificação Köppen, o DF tem clima tropical úmido com inverno seco. A carta bioclimática do DF, da ABNT NBR 15220-3, mostra que durante a maior parte do ano o território está dentro de zonas de conforto onde não são necessárias estratégias de condicionamento térmico, não sendo um limitante a ocupação urbana na região. Ainda, sobre as características da precipitação na região a média pluviométrica anual do Distrito Federal varia entre 1.200 e $1.500 \mathrm{~mm}$. Entretanto, as chuvas não são bem distribuídas durante o ano, o mês de janeiro apresenta o maior índice pluviométrico médio (248 mm/mês), enquanto os meses de junho, julho e agosto registram os menores índices $(11 \mathrm{~mm} / \mathrm{mês})$. Ainda, durante o período seco a insolação é maior que no período chuvoso devido à escassez de nebulosidade, acarretando numa maior evaporação da água (GDF \& Greentec, 2011). O resultado é um déficit de água no solo entre os meses de maio e outubro e um superávit entre novembro e abril. O que significa que no início do período chuvoso, o solo está com a umidade abaixo de sua capacidade de campo, de forma que os primeiros dias de chuvas contribuem apenas para recuperar sua umidade. Por outro lado, durante todo o período chuvoso, a taxa de infiltração nos solos pode ser reduzida devido à alta concentração de chuvas, que pode levar a saturação do solo. Em relação a distribuição das chuvas no território estudo de Gonçalvez (2007) 
demonstra que as chuvas são bem distribuídas, sendo que na maior parte do território há uma média pluviométrica anual de um mínimo de $1.100 \mathrm{~mm}$.

\section{Aplicação e Análise dos Resultados}

Para a construção do mapa de potencial de recarga e de potencial de urbanização foi feita a interpolação dessas características utilizando a metodologia de planejamento ecológico desenvolvida por Crepani et al (2001) descrita na seção anterior. Sendo que, a distribuição pluviométrica e características climáticas que influenciam no conforto da população foram desconsideradas devido sua alta variabilidade temporal e distribuição razoavelmente equânime pelo território (GONÇALVEZ, 2007).

Para a construção do mapa de recarga, os cinco compartimentos geomorfológicos do DF foram atribuídos valores de acordo como potencial de recarga de aquíferos com base na altitude relativa e declividade, tendo em vista influência dessas características na taxa máxima de entrada da água no solo e no fluxo vertical e lateral das águas subterrâneas. Os valores variam de 1 a 5 , sendo que 1 representa o menor e 5 o maior potencial para a recarga.

Tabela 2: Valoração quanto ao potencial de recarga das compartimentações geomorfológicas do Distrito Federal

\begin{tabular}{lllc}
\hline $\begin{array}{c}\text { Compartimentações } \\
\text { Geomorfológicas }\end{array}$ & \multicolumn{1}{c}{ Principais características } & $\begin{array}{c}\text { Potencial } \\
\text { de Recarga }\end{array}$ & \multicolumn{1}{c}{ Valor } \\
\hline Rampas Íngremes & $\begin{array}{l}\text { - Declividades superiores a 25\% } \\
\text { Vales Dissecados }\end{array}$ & $\begin{array}{l}\text { - Declividades superiores a 20\% } \\
\text { - Baixo regional, com cotas altimétricas inferiores a 800m }\end{array}$ & Muito baixo \\
Rebordos & - Declividades entre 10\% e 20\% & Baixo & 2 \\
Planos Intermediários & - Declividades inferiores a 12\% & Moderado & 3 \\
Planos Elevados & - Alto regional, com cotas altimétricas entre 950 e 1050m & Alto & 4 \\
\hline
\end{tabular}

Para os tipos de solos foram atribuídos valores representativos do potencial de recarga com base em suas características hidrológicas, principalmente a condutividade hidráulica e espessura, tendo em vista a influência desses fatores na infiltração e na capacidade de armazenamento. Os valores atribuídos também variam de 1 a 5 , sendo que 1 representa o menor potencial e 5 o maior.

Tabela 3: Valoração do potencial de recarga dos tipos de solo do Distrito Federal

\begin{tabular}{|c|c|c|c|}
\hline Tipos de solos & Principais características & $\begin{array}{c}\text { Potencial } \\
\text { de Recarga }\end{array}$ & Valor \\
\hline $\begin{array}{l}\text { Neossolos } \\
\text { Quartzarênicos }\end{array}$ & $\begin{array}{l}\text { - Solos muito profundos (> 200cm) } \\
\text { - Condutividade hidráulica próxima de } 2,8 \text { × 10-4 }\end{array}$ & Muito alto & 5 \\
\hline $\begin{array}{l}\text { Latossolos Vermelho e } \\
\text { Vermelho- Amarelo }\end{array}$ & $\begin{array}{l}\text { - Solos muito profundos }(>200 \mathrm{~cm}) \\
\text { - Condutividade hidráulica entre } 1,7 \text { x 10-5 a 10-6. }\end{array}$ & Alto & 4 \\
\hline $\begin{array}{l}\text { Argissolos vermelhos e } \\
\text { Nitossolos vermelhos }\end{array}$ & $\begin{array}{l}\text { - Solos profundos (entre } 100 \text { e } 200 \mathrm{~cm} \text { ) } \\
\text { - Condutividade hidráulica entre } 10-5 \text { e } 10-6 \mathrm{~m} / \mathrm{s}\end{array}$ & Moderado & 3 \\
\hline $\begin{array}{l}\text { Plintossolos Pétricos, } \\
\text { Gleissolo Háplico e } \\
\text { Neossolo Flúvico }\end{array}$ & $\begin{array}{l}\text { - Solos pouco profundos (entre } 50 \text { e } 100 \mathrm{~cm} \text { ) } \\
\text { - Condutividade hidráulica entre } 2,3 \text { x } 10-6 \text { a } 1,4 \text { × 10-7 }\end{array}$ & Baixo & 2 \\
\hline $\begin{array}{l}\text { Cambissolo Háplico e } \\
\text { Neossolo Litólico }\end{array}$ & $\begin{array}{l}\text { - Solos profundos a rasos (entre } 0 \text { e } 200 \mathrm{~cm} \text { ) } \\
\text { - Condutividade hidráulica entre } 10-7 \text { e } 10-8 \mathrm{~m} / \mathrm{s}\end{array}$ & Muito Baixo & 1 \\
\hline
\end{tabular}

De posse desses valores, que variam de 1 a 5 , se atribuiu duas variáveis, tipos de solos (Sr) e compartimentações geomorfológicas (Gr). Assim, o mapa de potencial de recarga dos aquíferos da pesquisa foi construído a partir do cruzamento dessas variáveis por meio de uma média ponderada, onde o peso dois atribuído aos tipos de solo ( $\mathrm{Sr}$ ) se deve a importância desse domínio para o processo de recarga reconhecido na literatura (LOUSADA; CAMPOS, 2005; SANTOS; KOIDE, 2016), utilizando a seguinte equação: 
$\operatorname{Pr}=\frac{2 S r+G r}{3}$

Onde:

$\operatorname{Pr}=$ Potencial de recarga dos aquíferos

$\boldsymbol{S} \boldsymbol{r}=$ Valores de potencial de recarga atribuídos aos tipos dos solos

$\boldsymbol{G r}=$ Valores de potencial de recarga atribuídos às compartimentações geomorfológicas

De posse dessa espacialização foi possível a classificação do potencial de recarga dos aquíferos do território em cinco grupos: (1) muito baixo (4,03\% do território); (2) baixo, (23,92\% do território); (3) moderado (10,60\% do território); (4) alto (37,44\% do território); (5) muito alto (22,02\% do território). Sendo que as áreas onde é mais importante manter as características naturais do solo e padrões de ocupação que permitam e/ou auxiliem a entrada natural de água da chuva são as regiões de alto e muito alto potencial, que juntas correspondem a $59,45 \%$ do território (figura 3 ).

Figura 5: Mapa de potenciais de recarga do Distrito Federal

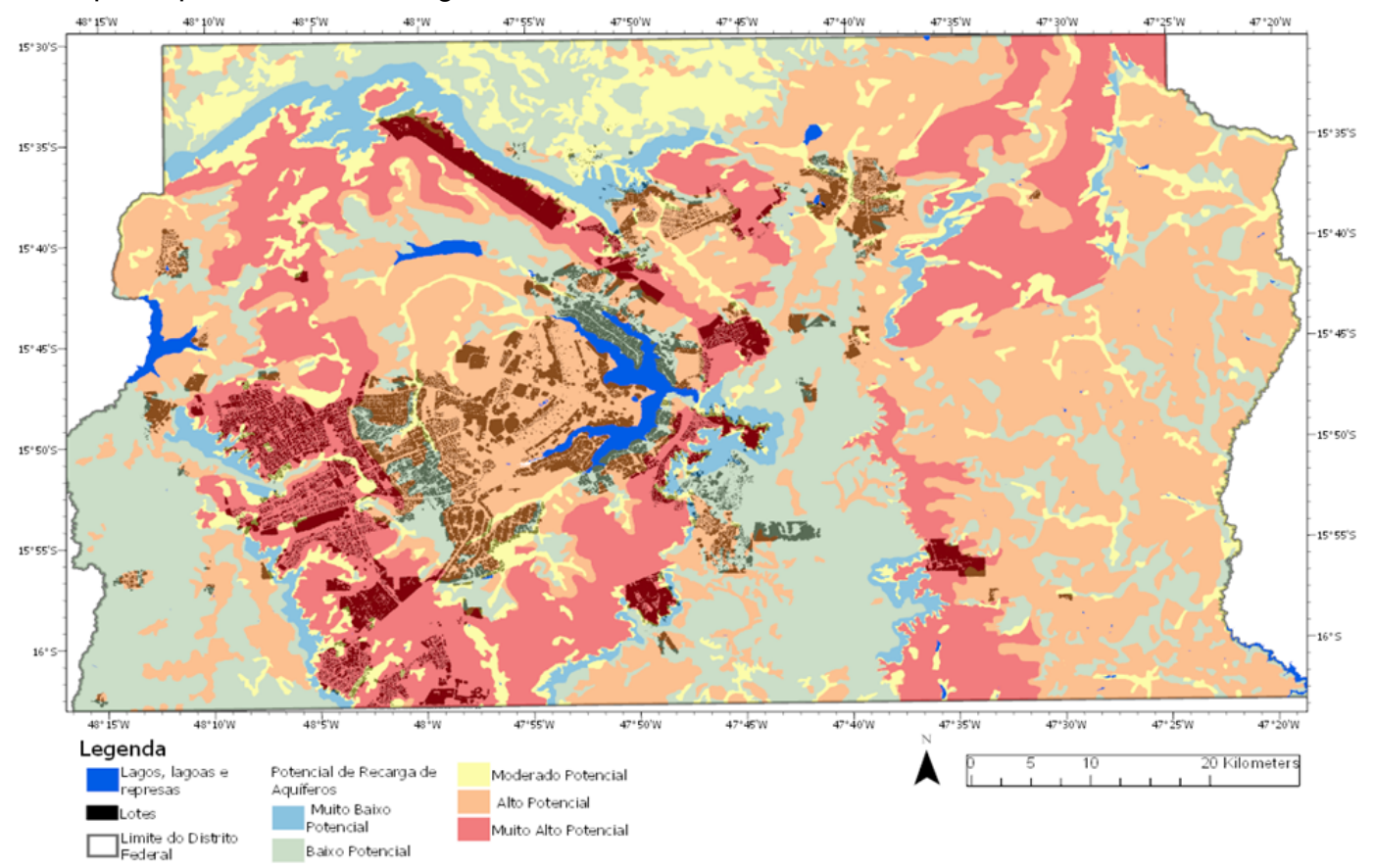

Para a construção do mapa de potencial de urbanização, aos compartimentos geomorfológicos foi atribuído uma variável representativa do potencial de urbanização com base na declividade, tendo em vista o impacto desse fator na possibilidade de mecanização e na possibilidade de ruptura e erosão do solo. As variáveis atribuídas variaram de 1 a 4 , sendo que 1 representa o menor potencial e 4 o maior.

Tabela 4: Valoração quanto ao potencial de urbanização das compartimentações geomorfológicas do Distrito Federal.

\begin{tabular}{llll}
\hline Compartimentações Geomorfológicas & \multicolumn{1}{c}{ Principais características } & $\begin{array}{c}\text { Potencial de } \\
\text { urbanização }\end{array}$ & \begin{tabular}{c} 
Valor \\
\hline Rampas Íngremes
\end{tabular} \\
Vales Dissecados & - Declividades superiores a 25\% & Baixo & 1 \\
Rebordos & - Declividades superiores a 20\% & Moderado & 2 \\
Planos Intermediários e Plano Elevados & - Declividades entre 10\% e 20\% & Alto & 3 \\
\hline
\end{tabular}

Para os tipos de solos também foi definido uma variável representativa do potencial de urbanização com base em sua resistência a cargas, permeabilidade e coesão. As variáveis atribuídas também variam de 1 a 4 , sendo que 1 representa o menor potencial e 4 o maior. 
Tabela 5: Valoração quanto ao potencial de urbanização dos tipos de solo do Distrito Federal.

\begin{tabular}{|c|c|c|c|}
\hline Tipos de solos & Principais características & $\begin{array}{l}\text { Potencial de } \\
\text { urbanização }\end{array}$ & Valor \\
\hline $\begin{array}{l}\text { Latossolos Vermelho e } \\
\text { Vermelho- Amarelo }\end{array}$ & $\begin{array}{l}\text { Solos porosos, bastantes permeáveis, pouco } \\
\text { plásticos, boa resistência à cargas e processos } \\
\text { erosivos }\end{array}$ & Muito alto & 4 \\
\hline Plintossolo Pétrico & $\begin{array}{l}\text { Solos pouco permeáveis, muito resistente à cargas e } \\
\text { processos erosivos }\end{array}$ & Alto & 3 \\
\hline $\begin{array}{l}\text { Cambissolo Háplico, } \\
\text { Nitossolo, Argissolo, } \\
\text { Neossolos Quartzarênicos }\end{array}$ & $\begin{array}{l}\text { Solos pouco à muito permeáveis, pouco resistentes e } \\
\text { suscetíveis a erosão }\end{array}$ & Moderado & 2 \\
\hline $\begin{array}{l}\text { Gleissolo Háplico e } \\
\text { Neossolo Flúvico }\end{array}$ & $\begin{array}{l}\text { Solos pouco permeáveis, frequentemente } \\
\text { encharcados, muito argilosos, muito plásticos e muito } \\
\text { pouco resistentes }\end{array}$ & Baixo & 1 \\
\hline
\end{tabular}

De posse dos valores de 1 a 4 atribuídos às variáveis dos tipos de solos (Su) e compartimentações geomorfológicas $(\mathrm{Gu})$, obteve-se uma média aritmética, em ambiente SIG, do nível de potencial de urbanização, utilizando a seguinte equação:

$P u=\frac{S u+G u}{2}$

Onde:

$\boldsymbol{P u}=$ Potencial de urbanização

$\boldsymbol{S u}=$ Valores de potencial de urbanização atribuídos aos tipos dos solos

$\boldsymbol{G u}=$ Valores de potencial de urbanização atribuídos às compartimentações geomorfológicas

De acordo com os resultados, o território se divide em quatro grupos quanto ao seu potencial de urbanização: (1) baixo (4,46\% do território); (2) moderado (19,75\% do território); (3) alto $(20,00 \%$ do território); (4) muito alto $(55,79 \%$ do território). Os dados confirmam a semelhança entre as áreas propícias à recarga e à urbanização, uma vez que as áreas de muito alto potencial para a urbanização estão completamente sobrepostas às áreas de alto e muito alto potencial de recarga e ainda se estendem sobre parte das áreas alto potencial à urbanização (figura 4).

Figura 6: Mapa de potenciais de urbanização do Distrito Federal

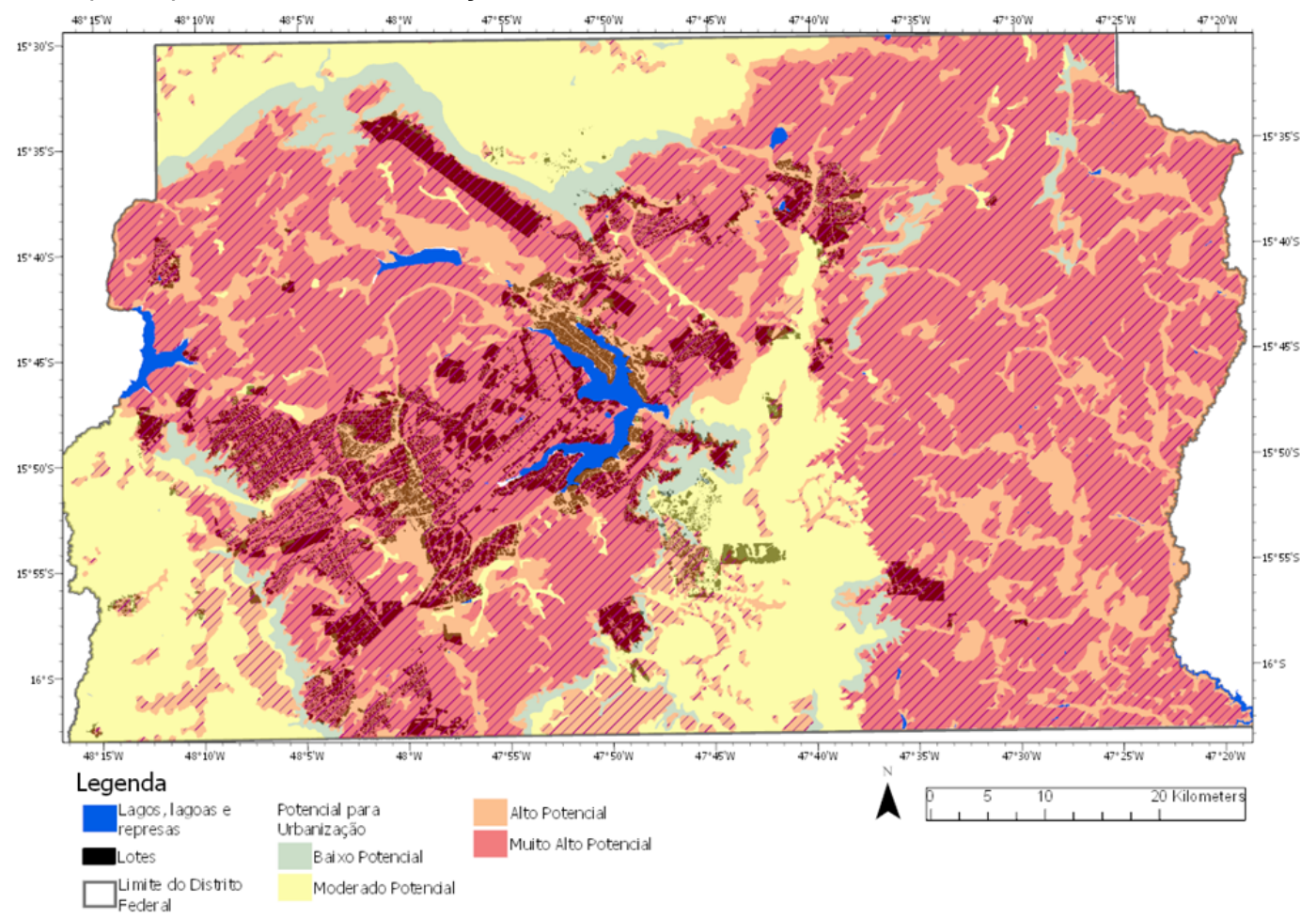


Para verificar ainda o processo de urbanização dessas áreas, foi feito o cruzamento dos mapas de potencial de recarga e de potencial de urbanização com os mapas de cobertura do solo no DF de 1953 e 2016, classificados em: (i) áreas urbanizadas; (ii) cobertura vegetal nativa e reflorestada; e (iii) outras áreas, como as com ocupações agropecuárias. $\mathrm{O}$ uso do solo foi agrupado nessas três categorias em função das diferentes relações que cada uma possui com o processo de recarga. Nas áreas urbanizadas, como visto, vários fatores contribui para redução da recarga e poluição dos aquíferos. Nas áreas de vegetação nativa a preservação do Cerrado é importante para o equilíbrio da produção de água. Como exemplo, um estudo realizado por Oliveira et. al (2015) demonstra taxas de infiltração de até $79 \%$ da chuva precipitada em áreas de cerrado de formação savânica, com 50 a $70 \%$ da área coberta por indivíduos arbóreos de 5 a $8 \mathrm{~m}$ de altura,. As áreas ocupadas com usos agropecuários, de mineração e chácaras de recreio foram identificadas para que toda a cobertura do solo do território fosse identificada, mas dados mais precisos sobre seu impacto na quantidade e qualidade de água nos aquíferos não foram objeto da presente pesquisa.

Para realizar a construção dos mapas de cobertura do solo foram utilizados dados do Siturb Sistema Informações Territoriais e Urbanas (áreas urbanizadas do ano de 2015); da Companhia de Planejamento do Distrito Federal - Codeplan (Cobertura vegetal nativa e reflorestada dos ano de 2016); da Organização das Nações Unidas para Educação, Ciência e Cultura - Unesco (Cobertura vegetal e urbana de 1953); e dados desenvolvidos pelas autoras (área urbanizada em 2016). O mapeamento das coberturas do solo no ano de 1953 foi feito com base na imagem do sobrevoo feito pela USAF (United States Air Force), onde a cobertura do solo foi classificada em: (i) mata, (ii) cerrado, (iii) campo, (iv) áreas urbanas e (v) área agrícola (VERÍSSIMO, 2002). As informações relativas à cobertura vegetal nativa e reflorestada de 2016 foram extraídas das imagens do satélite Landsat 8 e Landsat 5, que possuem sensores infravermelho OLI e Thematic Mapper (TM), onde a cobertura foi classificada a partir dessas bandas em: (i) formação florestal, (ii) formação savânica, (iii) formação campestre, (iv) reflorestamento; (v) área construída e (vi) área agropastoril (NEVES et al., 2016). A cobertura urbana de 2016 foi construída manualmente pelas autoras, com base em aerolevantamento de 2016 e a partir de uma revisão do levantamento da mancha urbana do Siturb para 2015, onde foram consideradas áreas urbanas formais e informais, contemplando lotes, vias, áreas comuns, áreas livres e áreas verdes, procurando utilizar o eixo das pistas que circundam esses elementos como delimitação e excluindo da mancha urbana unidades de conservação de proteção integral, áreas de preservação permanente desocupadas, lagos, lagoas e represas. Esses dados vetorizados e georreferenciados, foram cruzados com os mapas de potencial de recarga de aquíferos e de urbanização para montar cenários temporais de alteração da cobertura do solo sobre essas áreas, por meio do software ArcGIS.

A partir do cruzamento desses dados percebe-se que em 1953 apenas 259 hectares do território estavam urbanizados, crescendo 230 vezes até 2016, chegando a 59.733,86 hectares. As área urbanizadas em 2016 estavam distribuídas: 0,36\% sobre áreas de muito baixo potencial de recarga; $14,12 \%$ sobre áreas de baixo potencial de recarga; $4,25 \%$ sobre áreas de moderado potencial de recarga; $49,36 \%$ sobre áreas de alto potencial de recarga; e $31,88 \%$ sobre áreas de muito alto potencial de recarga; somando um total de $81,24 \%$ das áreas urbanizadas sobre áreas de alto e muito alto potencial de recarga e $90,70 \%$ sobre áreas de muito alto e alto potencial de urbanização, confirmando a premissa do estudo.

Quantos às áreas com cobertura vegetal nativa ou reflorestada, entre os anos de 1953 e 2016, percebe-se que $114.326,68$ hectares de vegetação nativa foi desmatada, entre os quais $58.222,59$ hectares foram desmatados sobre áreas de muito alto potencial de recarga e 44.504,41 sobre áreas de alto potencial de recarga. Ou seja, $90 \%$ de toda a cobertura vegetal nativa desmatada entre $1953 \mathrm{e}$ 2016 foi sobre áreas de alto e muito alto potencial de recarga. As áreas de vegetação nativa e reflorestada remanescentes em 2016 estavam distribuídas: 7,33\% sobre áreas de muito baixo potencial de recarga; $37,64 \%$ sobre áreas de baixo potencial; $14,70 \%$ sobre áreas de moderado 
potencial; $24,51 \%$ sobre áreas de alto potencial; e $15,71 \%$ sobre áreas de muito alto potencial; somando um total de $40,28 \%$ das áreas de vegetação nativa e reflorestada sobre áreas de alto e muito alto potencial de recarga.

Entre 1953 e 2016, o período de análise do estudo, a cobertura do solo do Distrito Federal passou de uma composição de $73,18 \%$ de cobertura vegetal nativa ou reflorestada, $0,04 \%$ de cobertura urbana e $26,77 \%$ de outras coberturas; para $51,34 \%$ de cobertura vegetal nativa ou reflorestada, $10,43 \%$ de cobertura urbana e $38,23 \%$ de outras coberturas. Nesses 63 anos $44,95 \%$ da área desmatada passou a ter uso urbano, enquanto $66,05 \%$ outros usos. Devida essas alterações, em 2016 , apenas $34,78 \%$ das áreas de alto e muito alto potencial de recarga ainda estavam cobertas por cobertura vegetal nativa ou reflorestada.

Figura 7: Mapa da cobertura do solo do DF em 1953. Própria autoria, com dados de VERÍSSIMO, 2002.

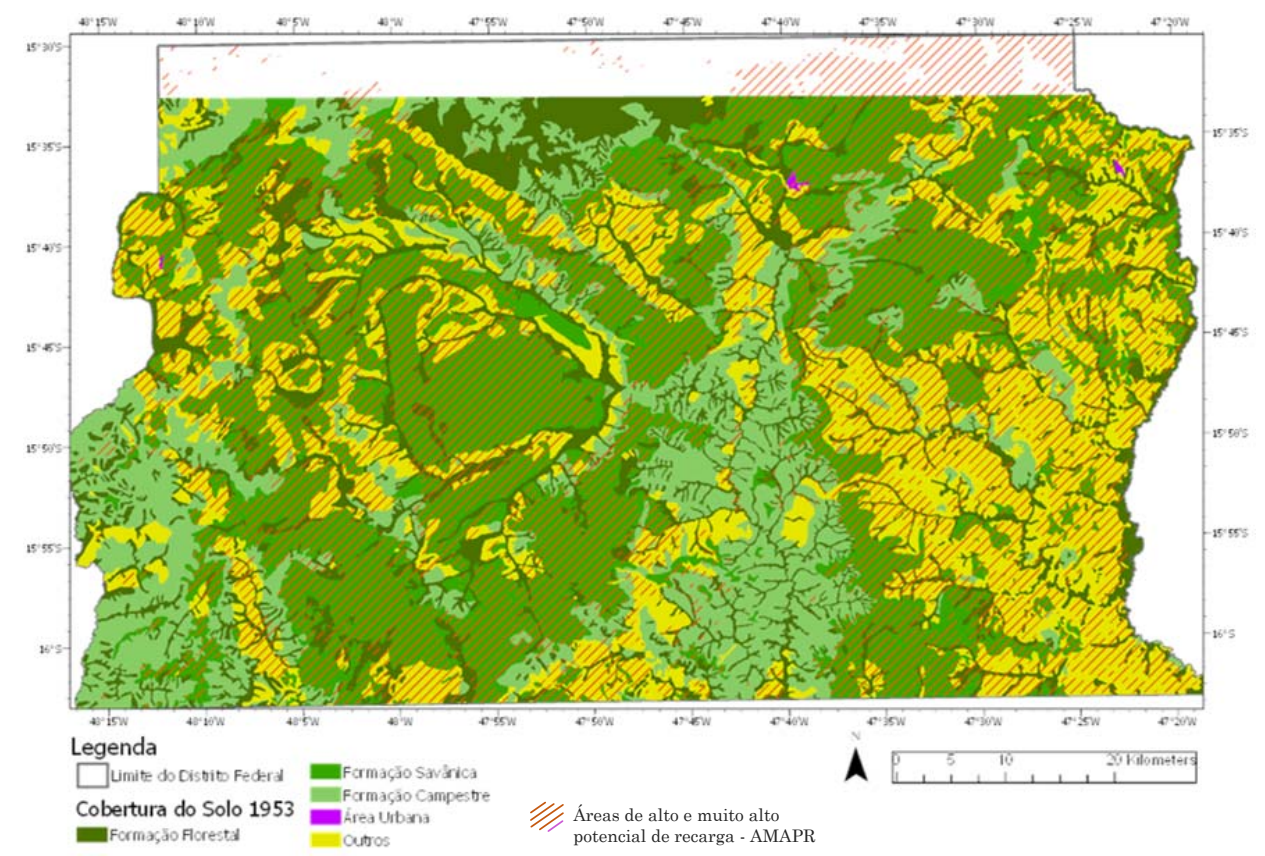

Figura 8: Mapa de Cobertura do solo do DF em 2016. Própria autoria, com dados de NEVES et al., 2016.

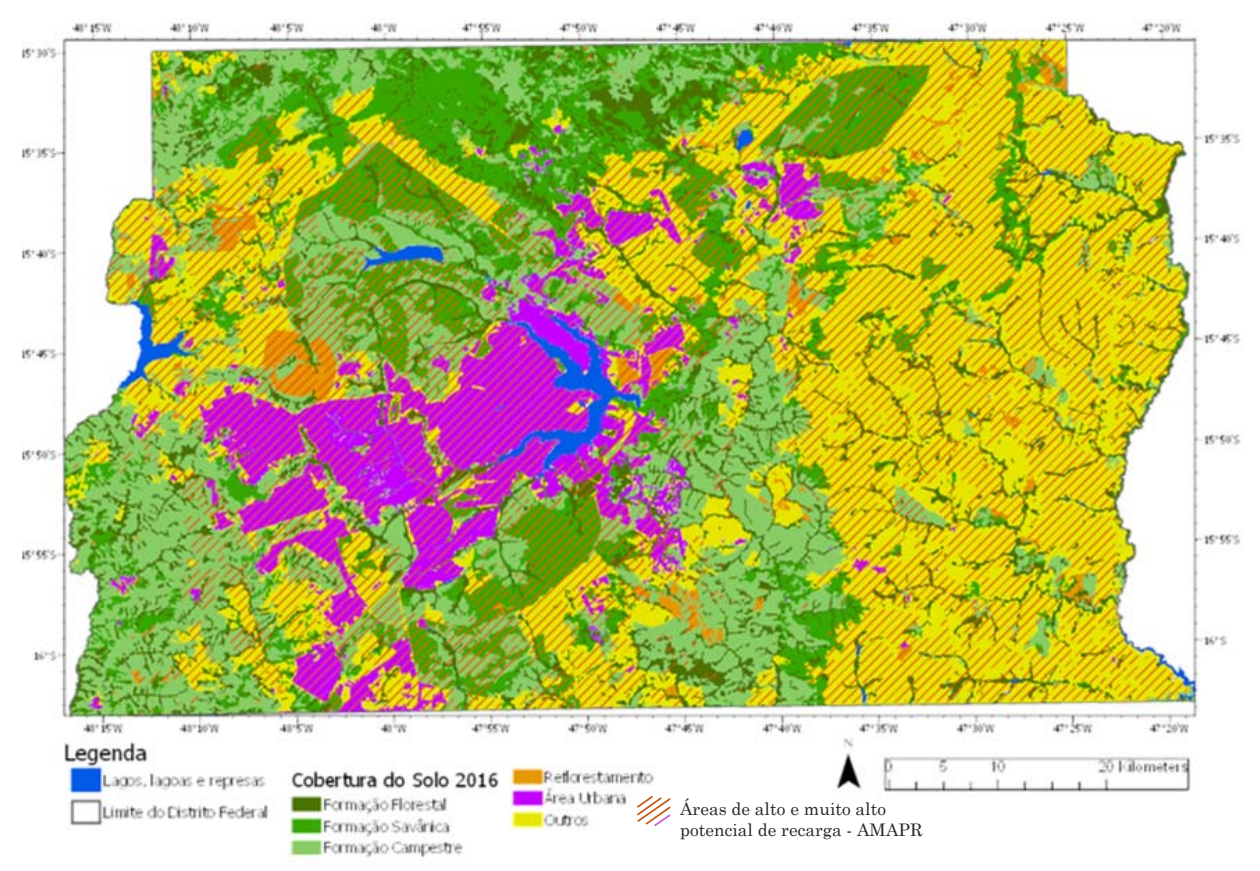




\section{Conclusão}

O estudo contribui para uma tomada de decisão mais assertiva em relação a utilização de padrões de ocupação do solo urbano que garanta o regime hidrológico mais próximo da natureza. Isso se dá por meio do uso da ferramenta espacial utilizada no estudo que permite a identificação das áreas de interseção entre áreas propícias à recarga de aquíferos e à urbanização, integrando estudos hidrogeológicos na incorporação de práticas de planejamento urbano intervenientes na gestão sustentável da água subterrânea no meio urbano.

Para construção da ferramenta, de acordo com o método proposto, foram revisadas as características do meio físico do território que condicionam o processo de recarga e o processo de urbanização. As condicionantes identificadas, para fins de metodizar a análise, foram organizadas em grupos de aspectos geomorfológicos (altitude relativa e declividade), pedológicos (condutividade hidráulica, espessura, coesão e resistência a cargas) e climáticos (disponibilidade hídrica e clima ameno) que devem ser avaliados para reconhecer as áreas propícias à recarga de aquíferos e à urbanização no território. A sobreposição desses dados deixa clara as similaridades entre as características que condicionam esses dois fenômenos, fazendo com que, em muitos casos,as áreas urbanas e de recarga se sobreponham. Esse fator aumenta a proporção do impacto da cidade sobre a função ecossistêmica de recarga dos aquíferos e demonstra a importância de considerar essa variável no planejamento urbano, principalmente quanto as formas de ocupação dessas áreas e escolha das áreas de expansão.

A verificação da consistência da metodologia proposta e das premissas da pesquisa, se deu a partir da aplicação da ferramenta de análise espacial no território do Distrito Federal. A partir do cruzamento dos dados do meio físico, para o DF,foi possível verificar que as áreas de alto e muito alto potencial de recarga, onde é importante a preservação das áreas naturais e ajuste dos padrões urbanos para que ocorra redução da perda de infiltração natural, ocupam $59,45 \%$ do território. Enquanto as áreas de alto e muito alto potencial de urbanização $75,59 \%$ do território, sendo que as áreas de muito alto potencial de urbanização estão totalmente sobrepostas às áreas de alto e muito alto potencial de recarga. Essa sobreposição dificulta a não ocupação urbana das áreas de recarga e demonstra necessidade do estudo e uso de técnicas de ocupação do solo urbano de menor impacto negativo à recarga.

As áreas de recarga de aquíferos do DF, vem experimentando intensas transformações de cobertura, devido um rápido processo de expansão urbana, de forma planejada e espontânea, e de consolidação de áreas agropecuárias. De forma que, em 2016, 81,24\% da área urbanizada do território estava sobreposta a áreas de recarga e $90 \%$ da cobertura vegetal nativa desmatada ocorreu também sobre essas áreas. Bem como as reduções nas vazões dos aquíferos próximos às áreas urbanizadas da região já se fazem notar nos últimos 15 anos, levando a crer que as mudanças na cobertura do solo vêm afetando a recarga. O que confirma a relevância do estudo em tela quanto a necessidade de conhecer e proteger a função de recarga dos aquíferos em áreas urbanas e permitir análise qualitativa do grau de comprometimento da recarga de aquíferos nas cidades.

\section{Referências}

ALMEIDA, G. C. P. de. (2004). Caracterização Física e Classificação dos Solos. Juiz de Fora: Universidade Federal de Juiz de Fora.

BARBIRATO, G. M.; TORRES, S. C.; SOUZA, L. C. L. (2011). Clima Urbano e Eficiência Energética nas Edificações. Rio de Janeiro: [s.n.].

BEAR, J. (2007). Hydraulics of Groundwater. 20 ed. Mineola, NY: Dover Publications.

CAMPOS, José Elói Guimarães. Hidrogeologia do Distrito Federal: Bases para a gestão dos Recursos Hídricos subterrâneos. Revista Brasileira de Geociências, v. 34, n. 1, p. 41-48], 2004.

CARTER, Harold. Urban Origins: a review. Progress in Human Geography, v. 1, n. 1, p. 12-32, 1977.

CREPANI, E. et al. Sensoriamento Remoto e Geoprocessamento Aplicados ao Zoneamento EcológicoEconômico e ao Ordenamento Territorial. INPE (INPE-8454-RPQ/722), p. 103, 2001.

FOSTER, Stephen; LAWRENCE, Adrian; MORRIS, Brian. Groundwater in Urban Development: 
Assessing Management needs and formulating policy strategies. Washington, D.C: [s.n.], 1998.

GDF; GREENTEC. (2011). ZEE - Subproduto 3.1 - Relatório do Meio Físico e Biótico. Brasília: [s.n.]. Disponível em: <http://www.zee-df.com.br>.

(GDF, 2017)

GONÇALVEZ, T. D. (2007) Geoprocessamento como ferramenta de apoio à gestão dos recursos hídricos subterrâneos do Distrito Federal. Dissertação de Mestrado. Universidade de Brasília UnB.

HINMAN, Curtis. Low Impact Development Technical Guidance Manual for Puget Sound.[S.I: s.n.], 2012

HOUGH, M. (1984). Cities and Natural Process: towards a new urban vernacular. 1. ed. [S.I.]: Croom Helm.

KALIRAJ, S.; CHANDRASEKAR, N.; MAGESH, N. S. (2014) Identification of potential groundwater recharge zones in Vaigai upper basin, Tamil Nadu, using GIS-based analytical hierarchical process (AHP) technique. Arabian Journal of Geosciences, v. 7, n. 4, p. 1385-140.

LETÃO, André Botequilha Leitão; AHERN, Jack. Applying landscape ecological concepts and metrics in sustainable landscape planning. Landscape and Urban Planning, v. 59, n. 2, p. 65-93, 2002.

LOUSADA, E. O.; CAMPOS, J. E. G. (2005). Estudos isotópicos em águas subterrâneas do Distrito Federal: subsídios ao modelo conceitual de fluxo.Revista Brasileira de Geociências, v. 41, n. 2, p. 355-365.

MARSALEK, Jiri et al. Urban Water Cycle Processes and Interactions. International Hydrological Programme (IHP). Paris, France: [s.n.], 2013.

MCHARG, I. L. (1969). Design with nature. [S.I: s.n.].

MELLO, R. M. E CASTRO, C M.S.N. Explotação de água subterrânea no Distrito Federal. Gestão por sistema hidrogeológico. In: Simpósio Brasileiro de Recursos Hídricos, 19... Anais... Maceiro: Associação Brasileira de Recursos Hídricos, 2011.

MOTA, S. (1981). Planejamento Urbano e preservação ambiental. Fortaleza, CE: Edições UFC.

NDUBISI, F. (2002). Ecological Planning: a historical and comparative Synthesis. Baltimore: Johns Hopkins University Press.

Oliveira et al. (2015)

SANTOS, R. M.dos; KOIDE, S. (2016). Avaliação da Recarga de Águas Subterrâneas em Ambiente de Cerrado com Base em Modelagem Numérica do Fluxo em Meio Poroso Saturado. Revista Brasileira de Recursos Hídricos, v. 21, n. 2, p. 451-465.

SILVEIRA, L.; USUNOFF, E. J. (2009). Groundwater: Encyclopedia of life support systems. Oxford, UK: [s.n.].

SERAPHIM, A. P. A. C. C. (2018). Relações entre as Áreas de Recarga dos Aquíferos e Áreas destinadas à Urbanização: Estudo dos Padrões de Ocupação do Solo da Unidade Hidrográfica do Paranoá - DF. Dissertação de mestrado. Programa de pós-graduação da Faculdade de Arquitetura da Universidade de Brasília.

SIMMERS, I. (1987). Estimation of Natural Groundwater Recharge. Antalya, Turkey: SpringerScience+Business.

SOUZA, M. M.de. (2013).Determinação das áreas de recarga para a gestão de sistema de aquífero físsuro-cárstico da região de São Sebastião/DF. Dissertação de Mestrado. $84 \mathrm{p}$. Instituto de Geociências da Universidade de Brasília.

SOUZA, Christopher Freire; CRUZ, Marcus Aurélio Soares; TUCCI, Carlos Eduardo Morelli. Desenvolvimento Urbano de Baixo Impacto: Planejamento e Tecnologias Verdes para a Sustentabilidade das Águas Urbanas. Revista Brasileira de Recursos Hídricos, v. 17, n. 2, p. 918, 2012.

TEIXEIRA, Wilson et al. Água Subterrânea. In: KARMANN, IVO (Org.). Decifrando a Terra. São Paulo: Oficina de Textos, 2000. p. 24. 